\title{
Knowledge, stress levels, and clinical practice modifications of Turkish dentists due to COVID-19: a survey study
}

\author{
Ayca SARIALIOGLU GUNGOR ${ }^{(a)}$ \\ Nazmiye DONMEZ ${ }^{(a)}$ (iD \\ Yesim Sesen USLU(b) iD
}

\footnotetext{
(a)Bezmialem Vakif University, Faculty of Dentistry, Department of Restorative Dentistry, Istanbul, Turkey

(b)|stanbul Okan University, Faculty of Dentistry, Department of Restorative Dentistry, Istanbul, Turkey
}

Declaration of Interests: The authors certify that they have no commercial or associative interest that represents a conflict of interest in connection with the manuscript.

\section{Corresponding Author:}

Ayca Sarıalıoglu Gungor

E-mail: asarialioglugungor@bezmialem.edu.tr

\section{Introduction}

An epidemic viral pneumonia of unknown etiology emerged in Wuhan, https://doi.org/10.1590/1807-3107bor-2021.vol35.0048

Submitted: June 15, 2020

Accepted for publication: December 12, 2020 Last revision: February 8, 2021 this pandemic, knowing the conditions about when the treatments can be applied and the precautions to be taken will shed light on dentistry staff. Current recommendations of national authorities about the coronavirus should be followed.

Keywords: COVID-19; Coronavirus; Dentistry; Dentists. China by the end of 2019. The pathogen causing the condition was called as the 2019 novel coronavirus (2019-nCoV), and the disease caused by this pathogen the 2019 coronavirus infectious disease (COVID-19). The human-to-human transmission rate of this virus increased significantly since mid-January 2020 and the disease spread rapidly throughout the world. ${ }^{1}$

On March 10, 2020, one day after the first coronavirus case was
Abstract: Dentists are exposed to the highest risk of occupational respiratory and droplet infections by working face-to-face with patients. The aim of this study was to investigate the knowledge of symptoms and modes of transmission of COVID-19, stress levels and clinical practice modifications of Turkish dentists during the COVID-19 pandemic. An online survey (15 questions) was sent to Turkish dentists from May 5 to 12 May, 2020. The survey comprised questions about dentists' demographic characteristics, their knowledge about COVID-19, stress levels and the measures taken in dental clinics against COVID-19. This study included a total of 1,095 Turkish dentists. The data were expressed as frequency with percentage values for overall variables. Dentists were most familiar with high fever among the symptoms of COVID-19 (99.4\%) and 99.2\% of them reported that COVID-19 was transmitted with eye, mouth and nasal mucosa contact on surfaces contaminated with the droplets of infected persons. While the stress levels of females were higher than males, the stress levels of dentists with more than 20 years of professional experience were found to be lower. Regarding the precautions to be taken as a preventive measure when working again, $86.6 \%$ of the dentists took precautions by increasing daily patient care intervals and only $38.4 \%$ of the dentists wore an N95 mask. During reported in Turkey, a global epidemic (pandemic) was declared by the 
World Health Organization (WHO) in the presence of 118,319 diagnosed cases and 4,292 deaths. In Turkey, all schools, including universities, were closed by March 13. All meetings, social gatherings, and indoor and outdoor public activities were restricted. Home isolation for individuals over the age of 65 and under 20 was enforced. All elective surgeries, including minimally invasive procedures, were postponed (excluding emergency cases). As of May 26, of this year, 157,814 coronavirus cases have been reported, with 4,369 deaths and 121,507 recoveries in Turkey. ${ }^{2}$

When a patient coughs, sneezes, talks or breathes, pathogen-laden droplets are released. ${ }^{3}$ It is widely known that the novel coronavirus can be transmitted mainly through direct contact and droplets. ${ }^{45}$ COVID-19 is also likely to spread through high concentrations of aerosols in a relatively closed environment. The use of high-speed dental equipments such as drills and aerators are currently considered to be aerosol generating procedures. This aerosol is potentially able to carry the virus causing COVID $-19 .{ }^{6}$ The dentist, staff, and patients are under a potential threat during routine dental treatments due to the aerosols formed. ${ }^{4}$ Dentists are at risk of contracting COVID-19 due to one-on-one communication with patients (entailing exposure to saliva, blood, and other body fluids) and the use of sharp instruments. In fact, it is has been reported that dentists are more likely to be infected by the novel coronavirus disease than doctors and nurses. ${ }^{7}$ Dentists can also be carriers of the disease. Although there has not yet been a report of the disease being transmitted from a dental treatment environment, given its high contagiousness, dental care teams should be cautious and provide a safe environment for both patients and themselves. In this critical process, understanding aerosol propagation and its importance in dentistry raises the necessity to apply some special measures in addition to those that are already standard. Due to aerosol production and exposure to saliva and blood, dental clinicians are at high risk of transmission during their routine dental treatments. ${ }^{8}$ Therefore, this situation can create anxiety and stress on dentists.

Traumatic events can decrease people's feeling of security, remind them of the reality of death and have adverse effects on their mental health. Many factors including can adversely affect stress levels and mental health of the people, some of them are: questions with no definite answers such as the end date of the epidemic and the appropriate methods of treatment, constant exposure to a flow of information about the epidemic and its effects, decreased social relationships and recommendations/prohibitions such as staying at home as much as possible. COVID-19 pandemic has led an increase in the frequency of symptoms such as anxiety, depression, fear, stress, and sleep problems. ${ }^{9}$ Family income stability and living with parents were found to be shielding from anxiety symptoms. ${ }^{10}$ Variables such as occupation, education, and gender affected the symptoms of anxiety and depression tend to be developed during the epidemic in different ways. ${ }^{11}$

To the best knowledge, psychological stress due to COVID-19 has not been assessed among Turkish dentists although it has done in other countries. ${ }^{8,12}$ The present study aimed to assess the anxiety and stress levels surrounding the threat of infection among dentists working during the current viral outbreak. In addition, dentists' knowledge about various practice modifications to combat the novel coronavirus disease (COVID-19) has been evaluated.

\section{Methodology}

All procedures conducted were approved by the Ethical Committee of Bezmialem Vakif University (06/107,05.05.2020).

Our study population consisted of dentists working in Turkey. At the time of the survey, dentists were not actively taking care of patients. Informed consent was obtained electronically before data were collected from the participants.

At the present time, most countries around the world are in lockdown conditions; therefore, it was not feasible to conduct physical interviews during this critical period. Instead, we decided to use an online platform to collect the necessary data. A new survey about COVID-19 was formed for our study. First, we carried out a PubMed search in English and Turkish for COVID-19-related content and guidelines by using the keywords "COVID-19," "coronavirus," "dentistry," "dental treatment," and "stress level" with 
and without Boolean operators. Survey questions were formed after reviewing the pertinent literature and the international guidelines. ${ }^{13,14,15}$

The questionnaire was designed in Turkish. Following Zhong et al., ${ }^{16}$ who studied the knowledge, attitudes, and practices of COVID-19 infected areas in China, and Ahmed et al., ${ }^{12}$ who investigated the presence of fear and practice modifications among dentists, we prepared a structured questionnaire with a combination of 20 multiple choice, open-ended, and Likert-type questions. The content adequacy of the survey was examined by experts to assess the clarity the wording of the items prior to the main study. The questions were sent to five experts (two restorative dentists, one endodontist, one general dentist, and one biostatistician). Based on their comments, five questions were removed. Then, the final 15 questions were tested in a pilot study with 10 participants. Based on the feedback from the pilot study, we finalized the questionnaire with 15 questions. The final questionnaire was sent to a Turkish language expert for validation and it was concluded at this stage. The questionnaire had four parts: a) dentist's demographic and professional characteristics (five questions); b) knowledge of COVID-19 and dentist's awareness of the incubation period, the symptoms of the disease, the mode of transmission, and preventive infection control measures (four questions); c) stress level (four questions); and d) adjustments in the clinical practice and attitude in the treatment of patients after the COVID-19 pandemic (two questions).

This self-reportable, online questionnaire form was designed using Google Forms (Alphabet Co., Mountain View, USA), and the link was shared among all Turkish dentists through several dentist-specific closed social media forums, email, WhatsApp, Facebook, Instagram, etc. We received responses through online survey submission. Anonymity was ensured, and no personal identification, such as IP address, email address, or user ID, were collected. A total of 1,095 Turkish dentists, all volunteers, answered the questionnaire. Participation was voluntary, and participants could withdraw from survey at any time. All participants provided informed consent prior to completing the survey. The form was posted on May 5, 2020 at 22:00, and the survey was closed on May 12, 2020 at 22:00.
We also included a section for rating the average perceived stress level experienced by dentists during the pandemic in Turkey. A 10-point Likert scale with four questions, where 0 referred to "not at all stressful," 5 referred to "moderately stressful," and 10 referred to "extremely stressful", ${ }_{17}$ was developed to evaluate the stress levels induced by the COVID-19 outbreak; this section asked questions about the suggested sources of stress emotions (e.g., "I am worried about getting infected"). A psychometric analysis for the scale was finally conducted. Factor analysis was applied to determine the sub-dimensions of the "stress scale" within the scope of the Validity-Reliability. Cronbach's Alpha coefficients were calculated within the scope of reliability analysis of the scale questions. The statistical significance level (a) was taken as 5\% in calculations. Cronbach's Alpha value for "stress scale questions" was found to be 0.782 (78.2\%). Accordingly, the Cronbach's Alpha value of these scale questions exceeding $75 \%$ indicates that the reliability of these questions (items) is high.

The sample size required for the study was calculated by a statician. The power analysis estimated that survey with 380 or more individuals were needed to have a $95 \%$ confidence interval, a population size of 30,128 dentists, with the real value within $\pm 5 \%$ of the surveyed value. However, 1,095 dentists who answered the web-based survey completely during the survey application period were included to increase the reliability of the findings. Based on the stratified random sampling method, the minimum number required was determined by considering the targeted sample size.

Data were analyzed using IBM SPSS Statistics for Windows, version 22.0. To handle missing data, direct deletion method was used and all surveys with invalid data were discarded from further analysis and statistical analysis were conducted based on a complete dataset. While evaluating the study data, the appropriateness of the parameters to normal distribution was evaluated with the Shapiro-Wilk test. Frequencies and percentages were used to describe the categorical data. Mann Whitney test was used to compare stress items between gender and institution groups. A Kruskal Wallis test was used to test differences of stress ratings between professional 
experience groups. Dunn's test was used as post hoc procedure after a significant effect. Significance was evaluated at the level of $\mathrm{p}<0.05$.

\section{Results}

Frequency distribution of the 1,095 dentists' demographic characteristics were presented in Table 1.

When evaluating the knowledge of the dentists about COVID-19 symptoms, it was seen that high fever is known with the highest rate (99.4\%) among all other

Table 1. Frequency distribution of dentists' demographic characteristics.

\begin{tabular}{|c|c|c|}
\hline Variable & $n$ & $\%$ \\
\hline \multicolumn{3}{|l|}{ Age (years) } \\
\hline 20-30 & 312 & 28,5 \\
\hline $31-40$ & 342 & 31,2 \\
\hline $41-50$ & 270 & 24,7 \\
\hline $51-60$ & 135 & 12,3 \\
\hline $61+$ & 36 & 3,3 \\
\hline \multicolumn{3}{|l|}{ Gender } \\
\hline Female & 702 & 64,1 \\
\hline Male & 393 & 35,9 \\
\hline \multicolumn{3}{|l|}{ Professional experience } \\
\hline $0-5$ & 274 & 25 \\
\hline $6-10$ & 165 & 15,1 \\
\hline $11-15$ & 162 & 14,8 \\
\hline $16-20$ & 190 & 17,4 \\
\hline $21-25$ & 114 & 10,4 \\
\hline $26+$ & 190 & 17,4 \\
\hline \multicolumn{3}{|l|}{ Working place } \\
\hline University-based hospitals & 263 & 24 \\
\hline Government hospitals & 179 & 16,3 \\
\hline Private hospitals/Medical centers & 338 & 30,9 \\
\hline Private practice & 298 & 27,2 \\
\hline Others & 17 & 1,6 \\
\hline \multicolumn{3}{|l|}{ Profession } \\
\hline General dental practitioner & 651 & 59,5 \\
\hline Oral maksillofacial surgeon & 56 & 5,1 \\
\hline Orthodontist & 51 & 4,7 \\
\hline Prosthodontist & 67 & 6,1 \\
\hline Periodontist & 57 & 5,2 \\
\hline Pedodontist & 59 & 5,4 \\
\hline Endodontist & 68 & 6,2 \\
\hline Restorative dentist & 80 & 7,3 \\
\hline Oral diagnosis and radiology & 6 & 0,5 \\
\hline
\end{tabular}

symptoms. Regarding the mode of transmission of COVID-19, 99.2\% (1,086) of the dentists thought that the disease was transmitted through eye, mouth, and nasal mucosa contact with contaminated surfaces. Of the participants, $100 \%$ (1095) thought that they could prevent infection by washing their hands with soap and water for at least 20 seconds. While $4.4 \%$ (48) of the dentists thought that a COVID-19 positive patient could be treated when the Reverse Transcription- Polymerase Chain Reaction (RT-PCR) test result was negative, $63.1 \%$ (691) thought treatment could be done 14 days after the RT-PCR test result was negative (Table 2).

The levels of stress about being infected ranged from 1 to 10 and the scores given by the participants were shown in Figure 1. The results showed that the dentists had the "extremely stress" from infecting their families $(28.4 \%, 311)$ and they had concerns regarding current or future financial and organizational difficulties $(27.3 \%, 299)$. The results of the comparative evaluation of the responses to the stress scale items according to gender, professional experience and the type of institution were shown in Figures 2, 3 and 4 . The level of stress related to family and patient safeties of dentists with $0-10$ years and 11-20 years of professional experience were found to be statistically similar ( $p>0.05)$, while the level of stress was found to decrease statistically in dentists with more than 20 years of professional experience $(p<0.05)$ (Figure 3). Post-hoc analyses showed that increases in stress regarding professional practice were significantly associated with the type of institution $(p<0.001)$ (Figure 4). Although the level of stress was higher among females than males (Figure 2), there was no statistical difference between females and males regarding their professional practice (concerns regarding current or future financial) $(p=0.074)$.

Regarding the precautions to be taken as a preventive measure in the clinic when working again, 86.6\% (948) of the dentists took precautions by increasing daily patient care intervals, $73.1 \%$ (800) reported that they would measure the fever of each patient coming into the clinic, $49.2 \%$ (539) would sterilize the clinical environment with UV systems, and 55.9\% (612) would use aerosol absorber machine. It was revealed that 90.9\% (995) would wear special protective masks, 
Table 2. Dentists' awareness about symptoms, mode of transmission, measures for prevention and dental treatment time of the COVID-19(+) patient.

\begin{tabular}{|c|c|c|}
\hline Variable & $n$ & $\%$ \\
\hline \multicolumn{3}{|l|}{ Symptoms of COVID-19 } \\
\hline High fever & 1088 & 99,4 \\
\hline Dry cough & 1073 & 98 \\
\hline Fatigue & 1010 & 92,2 \\
\hline Shortness of breath & 1082 & 98,8 \\
\hline Chest pain & 728 & 66,5 \\
\hline Runny nose & 257 & 23,5 \\
\hline Headache & 775 & 70,8 \\
\hline Lumbago & 332 & 30,3 \\
\hline Other & 125 & 11,4 \\
\hline \multicolumn{3}{|l|}{ Mode of transmission } \\
\hline Coughing and sneezing & 1078 & 98,4 \\
\hline Eye, mouth and nasal mucosa contact on surfaces contaminated with the droplets of infected persons & 1086 & 99,2 \\
\hline Having more than 15 minutes of contact with the infected person & 878 & 80,2 \\
\hline Being 1 meter or closer to the infected person & 942 & 86 \\
\hline Can be transmitted from animals to humans & 132 & 12,1 \\
\hline It does not transmit from human to human & 423 & 38,6 \\
\hline \multicolumn{3}{|l|}{ Measures for prevention in daily life } \\
\hline Washing hands with soap and water for at least 20 seconds & 1095 & 100 \\
\hline Using alcohol-based hand antiseptics & 1071 & 97,8 \\
\hline Avoiding contact with people with respiratory diseases & 833 & 76,1 \\
\hline Avoiding contact of the hands with mouth, nose and eyes as much as possible. & 1086 & 99,2 \\
\hline Not being in crowded places & 1083 & 98,9 \\
\hline Wearing a mask in public areas & 1052 & 96,1 \\
\hline We cannot be protected from COVID 19 infection & 10 & 0,9 \\
\hline \multicolumn{3}{|l|}{ Dental treatment time of the COVID-19(+) patient } \\
\hline When rRT-PCR test result is negative & 48 & 4,4 \\
\hline 14 days after rRT-PCR test result is negative & 691 & 63,1 \\
\hline 30 days after rRT-PCR test result is negative & 239 & 21,8 \\
\hline 14 days after home quarantine & 81 & 7,4 \\
\hline Other & 36 & 3,3 \\
\hline
\end{tabular}

$88 \%$ (964) would wear protective goggles, and $60.6 \%$ (664) would wear overalls, while $1.6 \%$ (18) were not considering taking extra measures (Table 3).

\section{Discussion}

The study aimed to provide an insight into the changes in Turkish dentists' clinics in the preparation period of returning to routine dental treatment practices after the peak of the COVID-19 epidemic in Turkey in May 2020. The first official COVID-19 case in Turkey was detected on March 10, 2020. The number of cases increased day by day and peaked in May. This study was carried out using a web-based survey made available between May 5 and 12, 2020.

Dentists have been shown to have a high risk of becoming infected with COVID-19 due to the aerosol spread when performing especially prosthetic, restorative, and endodontic treatments in their working conditions. ${ }^{15}$ The identification of such symptoms can help dentists to recognize the threat as early as possible and take the necessary precautions, which is a critical step in the management $t^{18}$ and control of the spread of the disease ${ }^{15}$. Similar to the results of 


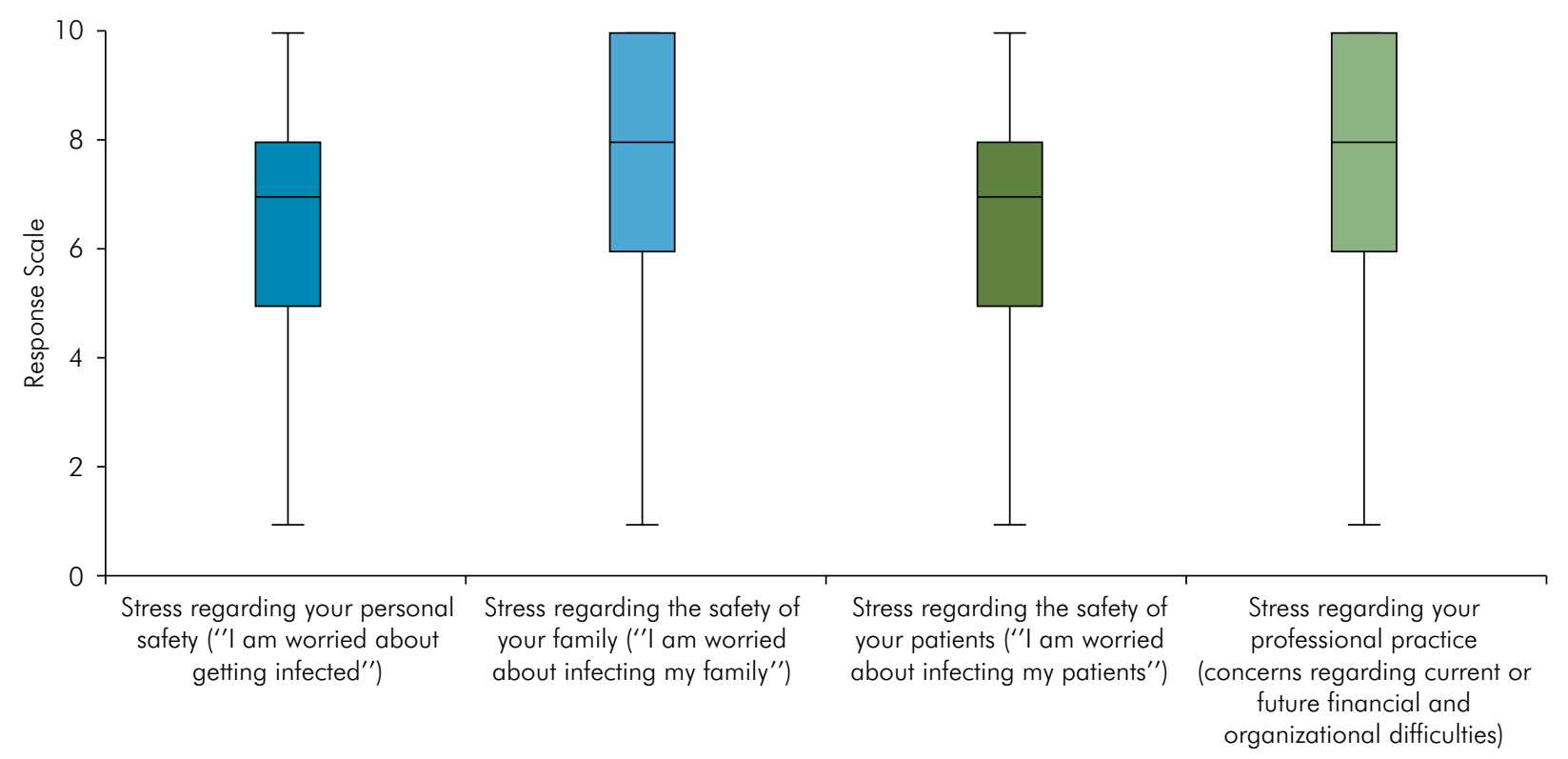

Figure 1. Distribution of perceived stress levels of dentists during the COVID-19 pandemic.

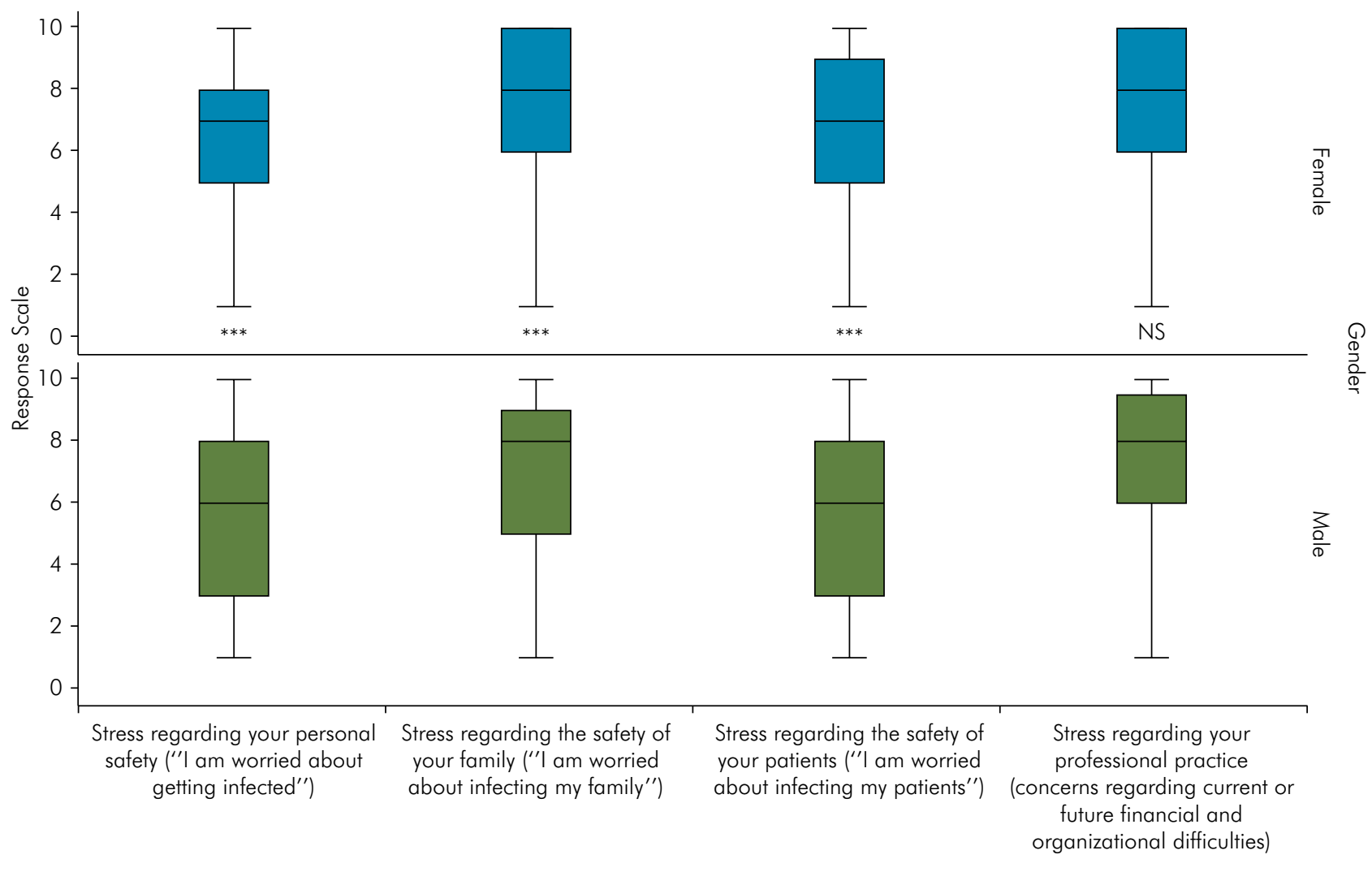

Figure 2. Box-plot representing the statistical relation of gender and stress scale responses. [Data represented as median (horizontal bars inside the box) and range (Y-error bars). ${ }^{* * *}=$ represents significant difference $(p<0.001)$. NS $=$ Non-significant $(p>0.05)$.

a study in the literature, ${ }^{19}$ Turkish dentists were able to identify the main symptoms of COVID-19, such as high fever (99.4\%), shortness of breath (98.8\%), dry cough (98\%), and fatigue (92.2\%) (Table 2). 


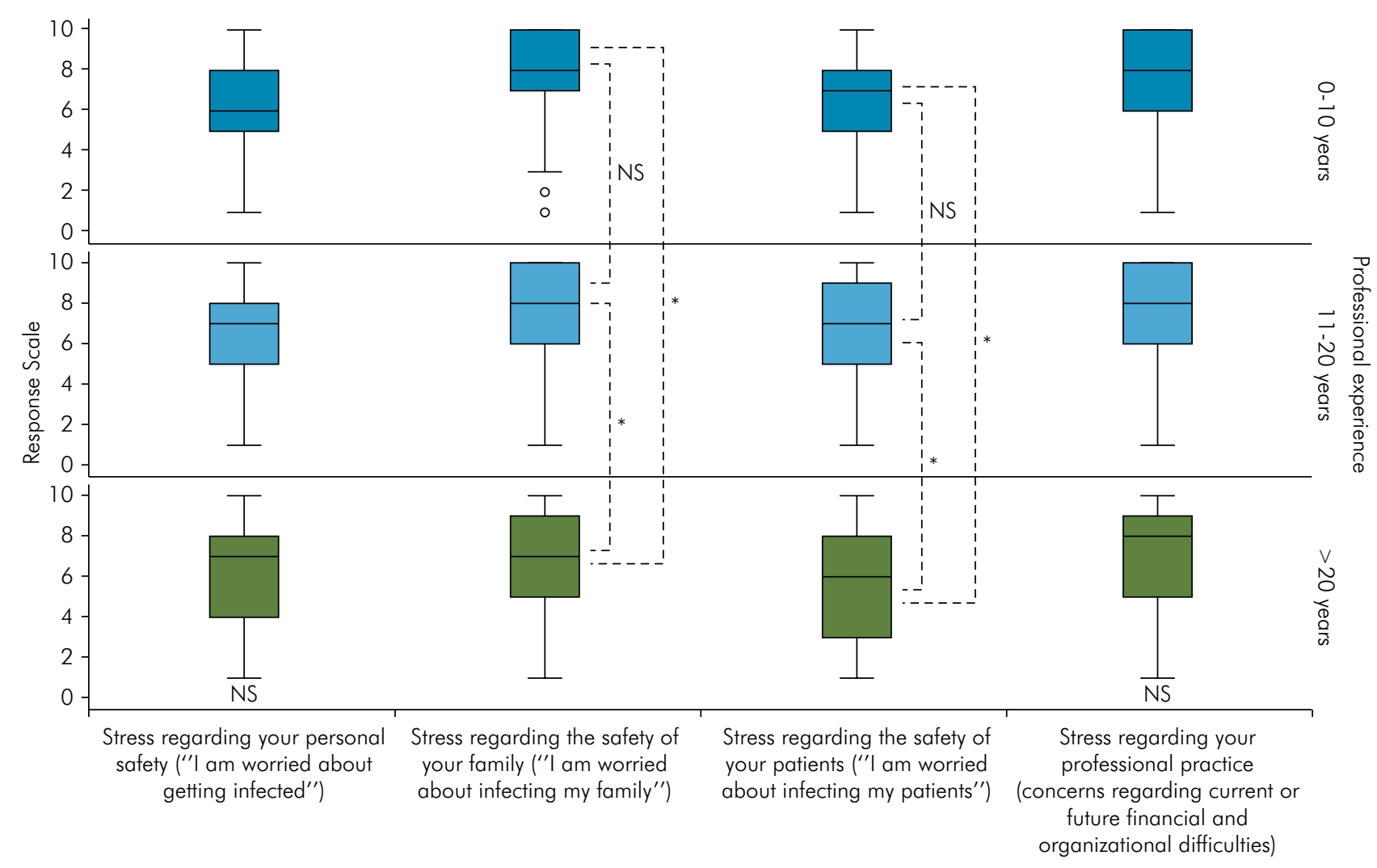

Figure 3. Box-plot representing the statistical relation of professional experience and stress scale responses. [Data represented as median (horizontal bars inside the box) and range (Y-error bars). ${ }^{*}=$ represents significant difference $(p<0.05)$. NS $=$ Non-significant $(p>0.05)$.

The Depression Anxiety Stress (DASS) scale consists of 42 questions. The high number of questions in the scale complicates the process of data collection and analysis. According to some authors, as the number of items on the scale increases, it tires the participants and provides less reliable answers. ${ }^{20,21} \mathrm{At}$ the same time, frequently asking similar questions to measure a particular dimension can be both tiring and disappointing, whereas measuring a dimension with less substance has the opposite effect. ${ }^{22}$ Therefore, in our study, we created our own stress scale (four questions) to determine the stress levels of dentists in relation to the COVID-19 pandemic.

Turkish dentists were found to be very concerned for their families and their stress levels exceeded the average stress value (Figure 1). Dentists were expected to be worried about getting infected with 2019-nCoV and transmitting it to their close family members. ${ }^{12}$ Additionally, incompatible with our results, Duruk et al., ${ }^{23}$ reported that facing COVID-19 contraction threat, most of dentists were concerned about their families and about themselves. The severity of psychological symptoms depends on age, gender, occupation, and proximity to the infected patient. ${ }^{24}$ Females were correlated to higher risk of experiencing anxiety and stress which may be due to the already reported gender difference for anxious and depressive symptoms. ${ }^{25}$ Previous studies claimed that females had higher depression and anxiety levels than male during the pandemic of COVID-19. ${ }^{26} 27$ However, it was also reported in a study that gender was not associated with anxiety and depression during the COVID-19 pandemic. ${ }^{28}$ Although our study revealed that female gender was associated with higher self reported anxiety and stress levels, there was no significant difference between females and males regarding current or future financial and organizational difficulties. Older people, city residents, and people with stable income present with low anxiety and depression. ${ }^{29}$ Educated young 


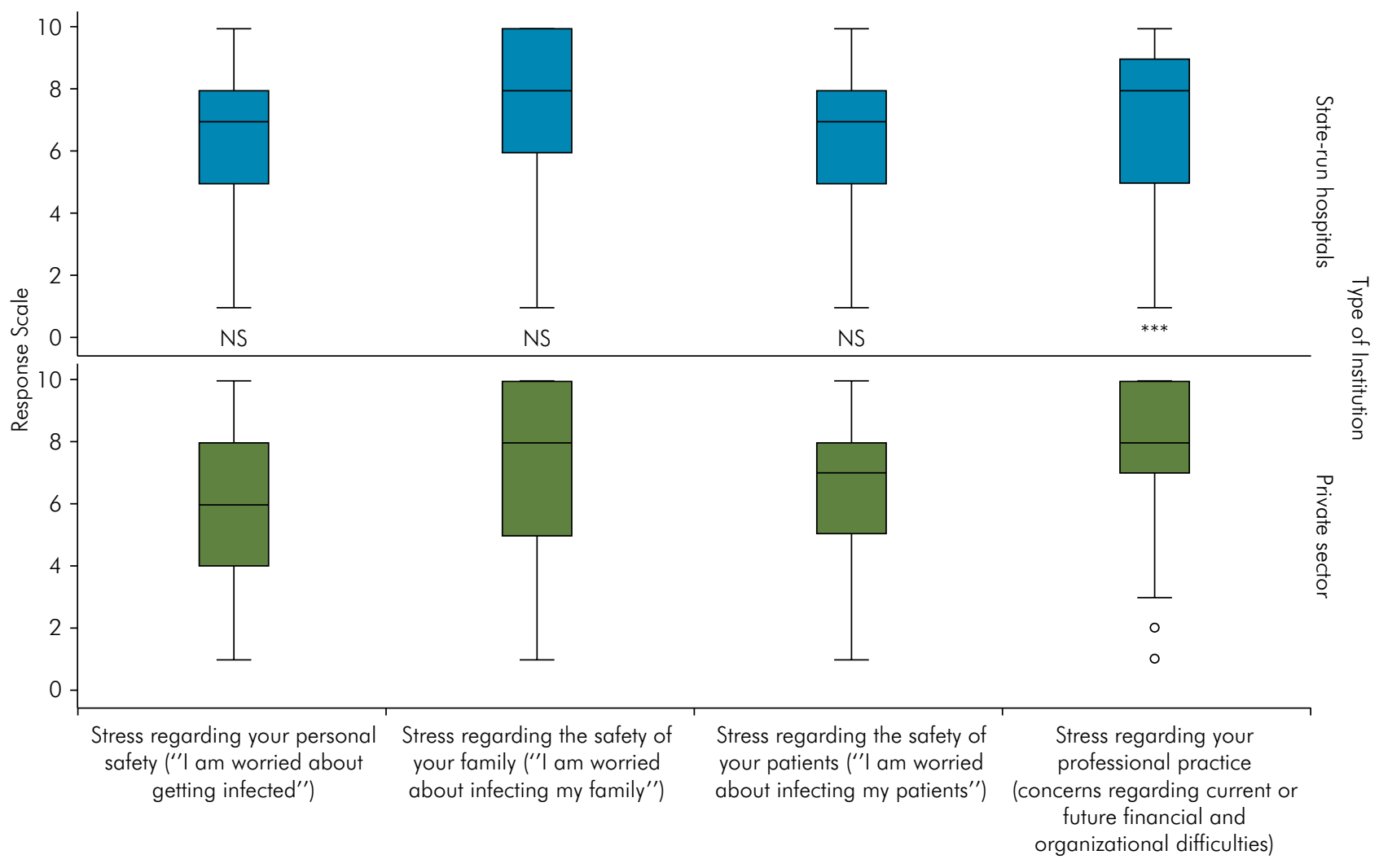

Figure 4. Box-plot representing the statistical relation of type of institution and stress scale responses. [Data represented as median (horizontal bars inside the box) and range (Y-error bars). ${ }^{* * *}=$ represents significant difference $(p<0.001)$. NS $=$ Non-significant $(p>0.05)$.

people are more likely to follow pandemic related news that increases the anxiety and stress levels. ${ }^{30}$ Current study showed that older dentists with more than 20 years of professional experience have lower stress levels than less experienced colleagues. Among dental staffs, being young and having less professional experience usually means low monthly income, lacking experience, and knowledge in dealing with terrible infectious diseases.

Researchers have revealed that the new type of coronavirus (SARS-CoV-2) that causes COVID-19 can live on different surfaces, such as metal, glass, or plastic, for hours and even up to nine days. ${ }^{31}$ Luckily, the virus can be efficiently inactivated within one minute by using surface disinfection products with $62-71 \%$ ethanol, $0.5 \%$ hydrogen peroxide, or $0.1 \%$ sodium hypochlorite. ${ }^{32}$ If soap and water are not available and hands are not visibly dirty, an alcoholbased hand sanitizer containing at least $60 \%$ alcohol can be used. However, visibly dirty hands should always be washed with soap and water. ${ }^{13}$ In our study, dentists considered that the most important measures for prevention against COVID-19 were "washing hands with soap and water for at least 20 seconds (sec) (100\%)" and "avoiding contact of the hands with mouth, nose, and eyes (99.2\%)" (Table 2). It is now confirmed that COVID-19 is transmitted through human contact and in the form of droplets, but airborne transmission is not rejected yet. ${ }^{33,34}$ Authorities recommended people to abstain from crowded places, including hospitals and dental clinics, as much as possible to guard against cross-infection resulting from the rapid transmission of COVID-19 since the end of January 2020. Similarly, in our study, avoiding crowded places $(98.9 \%)$ and wearing masks in public areas $(96.1 \%)$ were found to be the most effective protective measures to take by Turkish dentists (Table 2).

Of the dentists participated in this survey, at least $38.4 \%$ wore an N95 mask (Table 3 ). The reason behind 
Table 3. Personal protective equipment used by dentists and additional precautions to take as preventive measures against infection in clinics.

\begin{tabular}{|c|c|c|}
\hline Variables & $n$ & $\%$ \\
\hline \multicolumn{3}{|l|}{ Personal protective equipment } \\
\hline Gloves & 1061 & 96,9 \\
\hline Surgical mask & 956 & 87,3 \\
\hline N95 mask & 421 & 38,4 \\
\hline FFP2 / FFP3 respirator & 419 & 38,3 \\
\hline Safety goggles/ Face shield & 982 & 89,7 \\
\hline Overshoe & 821 & 75 \\
\hline Disposable apron & 274 & 25 \\
\hline Gown & 753 & 68,8 \\
\hline Overalls & 215 & 19,6 \\
\hline Other & 9 & 0,8 \\
\hline \multicolumn{3}{|c|}{ Precautions to be taken as a preventive measure to the clinic when working again } \\
\hline Increasing patient care intervals & 948 & 86,6 \\
\hline Measuring the fever of each patient coming to the clinic & 800 & 73,1 \\
\hline Sterilization of the clinical environment with UV systems & 539 & 49,2 \\
\hline Aerosol absorbing machine & 612 & 55,9 \\
\hline Special protective masks & 995 & 90,9 \\
\hline Wearing overalls & 664 & 60,6 \\
\hline Goggles & 964 & 88 \\
\hline I do not intend to take extra precautions & 18 & 1,6 \\
\hline Other & 44 & 4 \\
\hline
\end{tabular}

such an unexpected low rate could be the limited number of the masks and their high cost throughout the world ${ }^{35}$. Similarly, Khader et al. found $92.9 \%$ of dentists to wear personal protective equipment such as masks, gloves, and goggles, and $96.2 \%$ to frequently clean their hands using alcohol-based antiseptics along with soap and water. ${ }^{20}$ Furthermore, Khader et al. ${ }^{19}$ reported that although Jordanian dentists were beware of COVID-19 symptoms, its mode of transmission, infection control, and measures in dental clinics; they had limited comprehension of additional precautionary measures to protect the dental staff and patients from COVID-19. However, there were no "local" cases in Jordan at the time of data collection.

COVID-19 transmission can occur between humans who are in close contact (within about two meters) of each other. Additionally, the infected people who are infected but show no symptoms of the disease are also likely to play a role in the spread of COVID-19. ${ }^{36}$ People can spread the virus before they become aware of their sickness. Therefore, it is crucial to avoid contact with other people whether they show any symptoms or not. Social distancing can help to limit the contact with infected people and contaminated surfaces. There should be a distance of at least two meters between people and gathering in groups should be avoided to practice social or physical distancing. Social distancing is particularly important for people who carry higher risk due to their health conditions ${ }^{37}$ Similar to a study in the literature, ${ }^{23}$ our results showed that Turkish dentists believed in the importance of social distancing in mitigating the spread of the virus, and most of the dentists (86\%) thought that there should be at least one meter of distance from others who may be infected (Table 2).

Due to the possibility of COVID-19 recusancy and the fact that some viruses can be present in saliva for as long as 29 days after recovery ${ }^{38}$, it is important to be cautious when deciding upon the timing of non-emergency elective dental treatments of a COVID-19 (+) patient. A recovery is confirmed if the patient has been asymptomatic for at least 30 days after the last negative laboratory test. ${ }^{39}$ 
Knowing the dental treatment time of COVID-19 (+) patients can help in reducing and preventing new outbreaks. In our study, dentists mostly responded to the question on this topic by suggesting that procedures could be done 14 days after the rRT-PCR test result turned out to be negative (63.1\%) (Table 2). The lack of information on this issue may be due to the time it takes for symptoms to appear after confrontation with the virus, and the period within which symptoms appear can be extended up to 14 days. Also, the time that the virus stays in the saliva may not be known by dentists.

The main limitation of this study was the use of an adapted stress scale. Future studies should, if possible, employ other more objective questionnaire using a stress scale which has been proven to be reliable and valid. According to our findings, dentists' stress and anxiety levels related to COVID-19 had increased. Although the results here are similar to other studies in the literature, ${ }^{40,41}$ it still may not be possible to generalize on this issue, since we do not use all the questions of the perceived stress scale.

Another limitation of this study was the survey was conducted only with dentists in Turkey and not included all the dentists in Turkey. The results will likely vary according to the general conditions of each country and the degree of exposure to COVID-19. Therefore, the results of our study should be interpreted carefully and not be globalized. Even though the survey was sent to dentists all over Turkey, there was a lack of response and resultant small sample size. The reason for this could be that not all dentists use Internet and social media. It is aimed to carry out a study in which higher number of dentists are involved.

\section{Conclusion}

There has been a significant increase in stress levels due to the uncertainty of the working conditions of Turkish dentists during the COVID-19 pandemic period, as can be said to be the case with dentists all over the world. Accordingly, there will likely be an increase in the personal and professional protective measures that they will take when they return to their routine clinical practices. Further studies with more participants and longer follow-up term are needed to achieve more precise results.

\section{Acknowledgements}

The authors thank all participants for their valuable contribution to this study and all healthcare workers who devoted themselves to the coronavirus pandemic. The authors also would like to thank Ebru Osmanoglu from Variance Statistical Consultancy, who carried out statistical analysis.

\section{References}

1. World Health Organization - WHO. Infection prevention and control during health care when novel coronavirus (nCoV) infection is suspected: interim guidance. 2020 Mar 20 [cited 2020 May 20]. Available from: https://www.who.int/publications-detail/infectionprevention-and-control-during-health-care-when-novel-coronavirus-(ncov)-infection-is-suspected-20200125

2. World Health Organization - WHO. Coronavirus disease (COVID-19): situation report-127. 2020 [cited 2020 May 20]. Available from: https://www.who.int/docs/default-source/coronaviruse/situation-reports/20200526-covid-19-sitrep-127.pdf? sfvrsn=7b6655ab_8

3. Wang J, Chow TT. Numerical investigation of influence of human walking on dispersion and deposition of expiratory droplets in airborne infection isolation room. Build Environ. 2011;46(10):1993-2002. https://doi.org/10.1016/j.buildenv.2011.04.008

4. Ge ZY, Yang LM, Xia JJ, Fu XH, Zhang YZ. Possible aerosol transmission of COVID-19 and special precautions in dentistry. J Zhejiang Univ Sci B. 2020 May;21(5):361-8. https://doi.org/10.1631/jzus.B2010010

5. Smither SJ, Eastaugh LS, Findlay JS, Lever MS. Experimental aerosol survival of SARS-CoV-2 in artificial saliva and tissue culture media at medium and high humidity. Emerg Microbes Infect. 2020 Dec;9(1):1415-7. https://doi.org/10.1080/22221751.2020.1777906

6. Liyanage S, Ramasamy P, Elhaddad O, Darcy K, Hudson A, Keller J. Assessing visible aerosol generation during vitrectomy in the era of Covid-19. Eye (Lond). 2020 Jun; https://doi.org/10.1038/s41433-020-1052-4 Epub ahead of print.

7. Gamio L. The workers who face the greatest Coronavirus risk. New York Times, 2020 Mar 15 [cited 2020 May 20]. Available from: https://www.nytimes.com/interactive/2020/03/15/business/economy/coronavirus-worker-risk.html 
8. Consolo U, Bellini P, Bencivenni D, lani C, Checchi V. Epidemiological aspects and psychological reactions to COVID-19 of Dental practitioners in the Northern Italy districts of Modena and Reggio Emilia. Int J Environ Res Public Health. 2020 May;17(10):E3459. https://doi.org/10.3390/ijerph17103459

9. Torales J, O'Higgins M, Castaldelli-Maia JM, Ventriglio A. The outbreak of COVID-19 coronavirus and its impact on global mental health [published Online First: 2020/04/03]. Int J Soc Psychiatry. 2020 Jun;66(4):317-20. https://doi.org/10.1177/0020764020915212

10. Cao W, Fang Z, Hou G, Han M, Xu X, Dong J, et al. The psychological impact of the COVID-19 epidemic on college students in China. Psychiatry Res. 2020 May;287:112934. https://doi.org/10.1016/i.psychres.2020.112934

11. Wang Y, Di Y, Ye J, Wei W. Study on the public psychological states and its related factors during the outbreak of coronavirus disease 2019 (COVID-19) in some regions of China. Psychol Health Med. 2021 Jan;26(1):13-22. https://doi.org/10.1080/13548506.2020.1746817

12. Ahmed MA, Jouhar R, Ahmed N, Adnan S, Aftab M, Zafar MS, et al. Fear and practice modifications among dentists to combat novel Coronavirus disease (COVID-19) outbreak. Int J Environ Res Public Health. 2020 Apr;17(8):E2821. https://doi.org/10.3390/ijerph17082821

13. Centers for Disease Control and Prevention - CDC. Developing guidance regarding responding to COVID-19 in dental settings. Centers for Disease Control and Prevention; 2020.

14. World Health Organization - WHO. Clinical management of severe acute respiratory infection when novel coronavirus (nCoV) infection is suspected: interim guidance. Geneva: World Health Organization; 2020.

15. Meng L, Hua F, Bian Z. Coronavirus disease 2019 (COVID-19): emerging and future challenges for dental and oral medicine. J Dent Res. 2020 May;99(5):481-7. https://doi.org/10.1177/0022034520914246

16. Zhong BL, Luo W, Li HM, Zhang QQ, Liu XG, Li WT, et al. Knowledge, attitudes, and practices towards COVID-19 among Chinese residents during the rapid rise period of the COVID-19 outbreak: a quick online cross-sectional survey. Int J Biol Sci. 2020 Mar;16(10):1745-52. https://doi.org/10.7150/ijbs.45221

17. Korre M, Farioli A, Varvarigou V, Sato S, Kales SN. A survey of stress levels and time spent across law enforcement duties: police chief and officer agreement. Policing. 2014 May;8(2):109-22. https://doi.org/10.1093/police/pau001

18. Gaffar BO, El Tantawi M, Al-Ansari AA, AIAgl AS, Farooqi FA, Almas KM. Knowledge and practices of dentists regarding MERS-CoV: a cross-sectional survey in Saudi Arabia. Saudi Med J. 2019 Jul;40(7):714-20. https://doi.org/10.15537/smi.2019.7.24304

19. Khader Y, Al Nsour M, Al-Batayneh OB, Saadeh R, Bashier H, Alfaqih M, et al. Dentists' awareness, perception, and attitude regarding COVID-19 and infection control: cross-sectional study among jordanian dentists. JMIR Public Health Surveill. 2020 Apr;6(2):e18798. https://doi.org/10.2196/18798

20. Burisch M. Test length and validity revisited. Eur J Pers. 1997;11(4):303-15. https://doi.org/10.1002/(SICI)1099-0984(199711)11:4<303::AID-PER292>3.0.CO;2-\#

21. Gosling SD, Rentfrow PJ, Swann WB Jr. A very brief measure of the Big-Five personality domains. J Res Pers. 2003;37(6):504-28. https://doi.org/10.1016/S0092-6566(03)00046-1

22. Robins RW, Tracy JL, Trzesniewski K, Potter J, Gosling SD. Personality correlates of self-esteem. J Res Pers. 2001;35(4):463-82. https://doi.org/10.1006/irpe.2001.2324

23. Duruk G, Gümüşboğa ZS, Çolak C. Investigation of Turkish dentists' clinical attitudes and behaviors towards the COVID-19 pandemic: a survey study. Braz Oral Res. 2020;34:e054. https://doi.org/10.1590/1807-3107bor-2020.vol34.0054

24. Bohlken J, Schömig F, Lemke MR, Pumberger M, Riedel-Heller SG. [COVID-19 pandemic: stress experience of healthcare workers:a short current review]. Psychiatr Prax. 2020 May;47(4):190-7. German. https://doi.org/10.1055/a-1159-5551

25. Albert PR. Why is depression more prevalent in women? J Psychiatry Neurosci. 2015 Jul;40(4):219-21. https://doi.org/10.1503/ipn.150205

26. Wang C, Pan R, Wan X, Tan Y, Xu L, Ho CS, et al. Immediate Psychological Responses and Associated Factors during the Initial Stage of the 2019 Coronavirus Disease (COVID-19) Epidemic among the General Population in China. Int J Environ Res Public Health. 2020 Mar;17(5):6. https://doi.org/10.3390/ijerph17051729

27. Özdin S, Bayrak Özdin Ş. Levels and predictors of anxiety, depression and health anxiety during COVID-19 pandemic in Turkish society: the importance of gender. Int J Soc Psychiatry. 2020 Aug;66(5):504-11. https://doi.org/10.1177/0020764020927051

28. Chen Y, Zhou H, Zhou Y, Zhou F. Prevalence of self-reported depression and anxiety among pediatric medical staff members during the COVID-19 outbreak in Guiyang, China. Psychiatry Res. 2020 Jun;288:113005. https://doi.org/10.1016/i.psychres.2020.113005

29. González-Sanguino C, Ausín B, Castellanos MA, Saiz J, López-Gómez A, Ugidos C, et al. Mental health consequences during the initial stage of the 2020 Coronavirus pandemic (COVID-19) in Spain. Brain Behav Immun. 2020 Jul;87:172-6. https://doi.org/10.1016/j.bbi.2020.05.040

30. Ahmad AR, Murad HR. The impact of social media on panic during the COVID-19 pandemic in Iraqi Kurdistan: online questionnaire study. J Med Internet Res. 2020 May;22(5):e19556. https://doi.org/10.2196/19556

31. Suman R, Javaid M, Haleem A, Vaishya R, Bahl S, Nandan D. Sustainability of Coronavirus on different surfaces. J Clin Exp Hepatol. 2020 Jul-Aug;10(4):386-90. https://doi.org/10.1016/i.jceh.2020.04.020 
Knowledge, stress levels, and clinical practice modifications of Turkish dentists due to COVID-19: a survey study

32. Kampf G, Todt D, Pfaender S, Steinmann E. Persistence of coronaviruses on inanimate surfaces and their inactivation with biocidal agents. J Hosp Infect. 2020 Mar;104(3):246-51. https://doi.org/10.1016/i.jhin.2020.01.022

33. Guo H, Zhou Y, Liu X, Tan J. The impact of the COVID-19 epidemic on the utilization of emergency dental services. J Dent Sci. 2020 Dec;15(4):564-7. https://doi.org/10.1016/i.jds.2020.02.002

34. Li Q, Guan X, Wu P, Wang X, Zhou L, Tong Y, et al. Early transmission dynamics in Wuhan, China, of novel Coronavirus-infected pneumonia. N Engl J Med. 2020 Mar;382(13):1199-207. https://doi.org/10.1056/NEJMoa2001316

35. Mukerii S, Maclntyre CR, Seale H, Wang Q, Yang P, Wang X, et al. Cost-effectiveness analysis of N95 respirators and medical masks to protect healthcare workers in China from respiratory infections. BMC Infect Dis. 2017 Jul;17(1):464. https://doi.org/10.1186/s12879-017-2564-9

36. Backer JA, Klinkenberg D, Wallinga J. Incubation period of 2019 novel coronavirus (2019-nCoV) infections among travellers from Wuhan, China, 20-28 January 2020. Euro Surveill. 2020 Feb;25(5): https://doi.org/10.2807/1560-7917.ES.2020.25.5.2000062

37. Centers for Disease Control and Prevention - CDC. Coronavirus disease 2019 (COVID-19): Social distancing. Centers for Disease Control and Prevention; 2020. Available from: https://www.cdc.gov/coronavirus/2019-ncov/prevent-getting-sick/social-distancing.html

38. Zuanazzi D, Arts EJ, Jorge PK, Mulyar Y, Gibson R, Xiao Y, et al. Postnatal Identification of Zika virus peptides from saliva. J Dent Res. 2017 Sep;96(10):1078-84. https://doi.org/10.1177/0022034517723325

39. Alharbi A, Alharbi S, Alqaidi S. Guidelines for dental care provision during the COVID-19 pandemic. Saudi Dent J. 2020 May;32(4):181-6. https://doi.org/10.1016/j.sdentj.2020.04.001

40. Shacham M, Hamama-Raz Y, Kolerman R, Mijiritsky O, Ben-Ezra M, Mijiritsky E. COVID-19 factors and psychological factors associated with elevated psychological distress among dentists and dental hygienists in Israel. Int J Environ Res Public Health. 2020 Apr;17(8):E2900. https://doi.org/10.3390/ijerph17082900

41. Tran TT, Nguyen NB, Luong MA, Bui TH, Phan TD, Tran VO, et al. Stress, anxiety and depression in clinical nurses in Vietnam: a cross-sectional survey and cluster analysis. Int J Ment Health Syst. 2019 Jan;13(1):3. https://doi.org/10.1186/s13033-018-0257-4 